\title{
A taxa de câmbio no Mercosul: uma análise sob a ótica de cilcos políticos eleitorais
}

\author{
Camila Sá Teles ${ }^{1}$ \\ Jeruza Haber Alves ${ }^{2}$ \\ Stefan Wilson D'Amato
}

\begin{abstract}
Resumo:
O presente trabalho teve como objetivo verificar a influência dos Ciclos Políticos Eleitorais na taxa de câmbio dos países membros do Mercosul entre os anos de 1997 e 2014, utilizando dados em painel como método para a estimação. Os resultados apontam um ciclo eleitoral oposto à teoria: em períodos pré-eleitorais, a tendência tanto no bloco quanto nos países, é de depreciação cambial. Justifica-se tal comportamento com base na dinâmica da balança comercial dos países do Mercosul, sendo estes exportadores líquidos e, assim, induzindo os seus governantes a beneficiarem tal setor em suas medidas para angariar votos através da depreciação cambial.
\end{abstract}

Palavras-chave: Ciclos Políticos, Mercosul, taxa de câmbio.

The Mercosur exchange rate: an analysis under the optics of electoral political cycle

\begin{abstract}
:
The present study aimed to verify the influence of the Electoral Political Cycles on the exchange rate of Mercosur member countries between 1997 and 2014, using panel data as a method for estimation. The results are welcome to once, to a period as high as once, there is no block how much in the countries is depreciation exchange rate. Such behavior is justified on the basis of the dynamics of Mercosur's trade balance, these exporters being liquid and, as well as their rulers, a beneficiary in the sector in their measures to obtain votes through exchange depreciation.
\end{abstract}

Keywords: Political Cycles, Mercosur, exchange rate.

Classificação JEL: F31, D72

1 Possui Graduação em Economia pelo Departamento de Economia na área de Economia Internacional - Universidade Federal de Viçosa.E-mail: camila.teles@ufv.br

2 Possui graduação em Ciências Econômicas pela Universidade Federal de Viçosa(2012) e mestrado em Economia pela Universidade Federal de Viçosa(2014). Atualmente é Estudante de Doutorado da Universidade Federal de Viçosa e Professor Substituto da Universidade Federal de Viçosa, no Departamento de Economia. E-mail: jeruzahaber.alves@yahoo.com.br

3 Possui Graduação em Ciências Econômicas pela UFOP (Universidade Federal de Ouro Preto. É Mestre em Economia pelo Departamento de Economia (DEE) da UFV (Universidade Federal de Viçosa) com área de concentração em Desenvolvimento Econômico e Políticas Públicas e linha de pesquisa em Modelos Econômicos Aplicados. Atualmente, é doutorando em Economia pelo CEDEPLAR/UFMG.E-mail: tefimsl@hotmail.com 


\section{Introdução}

Em março de 1991, os países da América do Sul - Argentina, Brasil, Paraguai e Uruguai - assinaram o Tratado de Assunção visando à criação do Mercado Comum do Sul (Mercosul). Seu principal objetivo era a integração dos Estados Parte por meio da livre circulação de bens, serviços e fatores produtivos, como também o estabelecimento de uma Tarifa Externa Comum (TEC), a adoção de uma política comercial regular, a coordenação de políticas macroeconômicas e setoriais e a harmonização de legislações nas áreas pertinentes.

Assinado em 1994, a atual configuração do bloco é regida pelo Protocolo de Ouro Preto, que confere respaldo jurídico em caráter internacional ao bloco, atribuindo-lhe, assim, competência para negociar, em nome próprio, acordos com terceiros, grupos de países e organismos internacionais. O Mercosul possui ainda, como característica-chave, o regionalismo aberto, ou seja, tem por meta não só o florescimento do comércio intrazona, mas também o estímulo ao intercâmbio com outros parceiros comerciais.

Em 2012, o bloco passou pela primeira ampliação desde sua criação, com o ingresso definitivo da Venezuela. Com essa incorporação, o Mercosul passou a contar com uma população de 270 milhões de habitantes (70\% da população da América do Sul); Produto Interno Bruto (PIB) de US\$ 3,2 trilhões (80\% do PIB sul-americano); e território de 12,7 milhões de $\mathrm{km}^{2}$ ( $72 \%$ da área da América do Sul). Além do protagonismo exercido pela produção agrícola dos demais Estados Parte, o Mercosul passou a ser o quarto produtor mundial de petróleo bruto, somente atrás de Arábia Saudita, Rússia e Estados Unidos.

Todos os países do bloco possuem uma economia fortemente puxada pelas exportações, principalmente de commodities. De acordo com o Informe Mercosul $\mathrm{N}^{\mathrm{o}}: 19$, publicado anualmente pelo Instituto para a Integração da América Latina e o Caribe (BID-INTAL) no ano de 2013, as exportações do Mercosul totalizaram US $\$ 432$ bilhões de dólares contra as importações, que foram de US\$ 393 bilhões.

Ainda segundo o informe, os produtos naturais que representavam, em 2003, cerca de 70,5\%, foram ampliados para 78,6\% no ano de 2013, devido à elevação dos preços das commodities e ao aumento da demanda mundial, sustentada pela expansão das exportações do bloco. Além disso, notou-se o aumento da participação do setor de energia - puxado pela Venezuela e, em menor parte, pelo Brasil -, como também do minério de ferro brasileiro. Por outro lado, a parcela das exportações da soja apresentou um aumento de 1 p.p. durante a última década, tornando-se o segundo produto com maior expressão nas exportações do Mercosul.

Atualmente, todos os países sul-americanos são integrantes do Mercosul. Chile e Peru ingressaram como Estados Associados em 1996 e 2003, respectivamente. A Colômbia e o Equador já compõem o quadro de países desde 2004, seguidos por Guiana e Suriname, que se associaram em 2013. Por fim, temos a Bolívia, membro mais novo do bloco, que entrou no Mercosul em julho de 2015. 
A Presidência rotativa pro tempore do Mercosul é a máxima representação jurídico-política do Mercosul. O cargo é exercido durante o período de seis meses por um chefe de Estado de um dos países membros. Já foi assumida doze vezes pela Argentina, Brasil, Paraguai e Uruguai, e apenas uma vez pela Venezuela.

Barros (2009) apresenta que a coordenação das políticas macroeconômicas entre os países membros do bloco sempre despertou ressalvas entre seus negociadores, principalmente sobre a política cambial, haja vista a relevância desta no comércio internacional dentro e fora do Mercosul. Quanto maior a paridade das moedas locais entre si, maior o processo de integração comercial que favorece o desenvolvimento comercial das economias atuantes.

A teoria econômica dita que, em regimes cambiais de flutuação administrada - caso da Argentina e do Uruguai -, os Bancos Centrais passem a interferir nos mercados de câmbio apenas com o fim de evitar movimentos desordenados ou prejudiciais às suas economias. Entretanto, a formulação de políticas econômicas de cada país tende a ser feita de forma normativa, levando em consideração aspectos externos àqueles ditos como relevantes pela teoria, inclusive os que são de interesse dos formuladores dessas políticas.

O histórico dos países latino-americanos, mais particularmente dos sul-americanos, é marcado pelo uso das taxas de câmbio como ferramenta de controle inflacionário por governos populistas, principalmente os que se instauraram nas décadas de 80 e 90 na região, período no qual havia altas taxas de inflação e sérios descontroles orçamentários. O processo de ancoragem cambial utilizado para controle de inflação consistia basicamente no congelamento do câmbio nominal para fixação de preços internos nas moedas locais, garantindo uma estabilidade às grandes oscilações nos valores das mercadorias. Os estudos apontam que o fortalecimento das exportações e o desempenho positivo das transações comerciais entre os membros e associados do Mercosul estão intrinsecamente relacionados à boa gestão cambial destes.

Assim, a investigação sobre os reais determinantes da taxa de câmbio nesses países torna-se um interessante objeto de estudo sob a ótica dos Ciclos Políticos Eleitorais. A abordagem adotada infere, em linhas gerais, que os formuladores de políticas públicas são conhecedores dos aspectos que maximizam a aprovação de seus governos e, consequentemente, sabem quando a satisfação do eleitor atinge valores ótimos. Para o candidato ao governo, o grau de aprovação da sua gestão é dado com base na popularidade de suas políticas econômicas.

Dessa forma, a criação e a manutenção de políticas públicas por parte de representantes políticos que possuam como único interesse a maximização de votos e o arrebatamento de eleitores torna-se viável e real, a fim de obter uma possível reeleição ou eleição de sucessores. Tal fenômeno tem levantado o interesse de uma corrente de pensadores e sugere a existência de variações cíclicas de expansão e retração da economia em sincronia com períodos pré e pós-eleitorais.

A Teoria dos Ciclos Políticos foi apresentada primeiramente por Downs (1957). 
Ele pretendia analisar o ponto de interação entre agentes públicos e sociedade, tendo o bem-estar coletivo como variável de controle. $\mathrm{O}$ autor apontou que esse encontro de interesses ocorria em épocas de eleição, mais precisamente quando o atual governante conquistava uma reeleição. Já em 1975, partindo do trabalho de Downs (1957), Nordhaus elaborou, de fato, a Teoria dos Ciclos Políticos, que posteriormente abrangeria ramificações, como os Ciclos Políticos Partidários (HIBBS, 1977) e os Ciclos Políticos com expectativas Racionais (ROGOFF; SILBERT, 1988).

Dadas as características históricas e culturais dos países analisados, será adotada no presente trabalho a ideia inicial da teoria, concebida por Nordhaus (1975), que investiga a incidência de ciclos políticos oportunistas nas economias. Nessa literatura, o gestor de políticas públicas visa somente ao interesse próprio a qualquer custo. Assim, ele age através da manipulação dessas políticas para maximizar os votos do eleitorado. Este, por sua vez, adota características denominadas pelo autor como "míopes" e, também, toma suas decisões com base em fatos passados recentes, sem considerar possíveis ações futuras ou realizadas num certo período de tempo no passado.

Partindo da ideia de que os formuladores de políticas não estão unicamente preocupados com a maximização do bem-estar social, questiona-se se os eventos eleitorais são importantes para explicar os movimentos na média da taxa de câmbio dos cinco países membros do Mercosul - Argentina, Brasil, Paraguai, Uruguai e Venezuela.

Existe uma vasta literatura sobre a influência dos ciclos políticos na economia de um país ${ }^{4}$, assim como estudos sobre fatores econômicos e políticos que determinam o regime cambials. É possível encontrar trabalhos que tratam dos determinantes da taxa de câmbio (BLOMBERG; HESS, 1997; FRIEDEN; STEIN, 2001), e outros que estudam a volatilidade (LOBO; TUFTE, 1998; LENBLANG; BERNHARD, 2006), mas há também os que estudam o nível, (HUANG; TERRA, 2016), assim como o desalinhamento do nível de equilíbrio (BONOMO; TERRA, 1999).

Remmer (1993), em seu ensaio para a América Latina, analisou a presença de ciclos políticos na expansão monetária, o superávit fiscal e a taxa de câmbio para alguns países de 1980 a 1991, porém seus resultados não se mostraram condizentes com a literatura, apontando uma depreciação cambial no momento anterior às eleições na maior parte de sua amostra. Além disso, Stein e Streb (2004), em uma análise empírica também para a América Latina, trabalharam com a hipótese de desvalorização no período pós-eleitoral e foram encontrados resultados que comprovaram esse fato.

Bonomo e Terra (1999) realizaram um ensaio para o Brasil, de 1964 a 1997, a fim de verificar a relação entre o regime de governo adotado e os níveis da taxa

4 Ver Nordhaus (1975), Hibbs (1977) e Alesina (1987).

5 Ver Berdiev, Kim, Chang (2012), Aliyen (2014) e Rodriguez (2016). 
de câmbio. Os resultados encontrados evidenciam uma tendência de que governos ditatoriais visem manter taxas de câmbio apreciadas. Já em períodos democráticos, ocorre uma valorização da taxa de câmbio nos períodos precedentes às eleições.

Frieden e Stein (2001) questionaram, em seu trabalho empírico, se as eleições são importantes para influenciar o tipo de regime cambial adotado em alguns países da América Latina. Os resultados encontrados indicam que, de fato, há um viés político na determinação dessas variáveis em períodos eleitorais. Tratando-se de economias abertas, os autores postulam que haveria um trade-off entre a competitividade do produto doméstico (fortalecido por desvalorizações na moeda local) e a inflação.

Considerando a problemática que envolve o comportamento oportunista, o presente trabalho se propõe a investigar a influência das eleições nos movimentos da média da taxa de câmbio para o Mercosul. A escolha do bloco está baseada em sua importância ao comércio global e na grande relevância que exerce no total das transações comerciais ocorridas na América do Sul.

Toma-se como hipótese que há uma manipulação sistemática da taxa de câmbio por parte dos gestores políticos em períodos eleitorais, com o interesse de maximizar votos para si e seus aliados. Assim, espera-se verificar que as decisões acerca da valorização e desvalorização do câmbio são guiadas também pelo fator político e não somente pelo econômico. A pesquisa contribuirá para enriquecer a literatura existente sobre o tema ao avançar o estudo no período de 1997 a 2014, já que tal abordagem ainda não foi aplicada a esse bloco econômico nesse recorte de tempo.

\section{Referencial teórico}

\subsection{A Teoria dos Ciclos Políticos}

A Teoria dos Ciclos Políticos deu origem aos Modelos Clássicos (ou Tradicionais) e aos Modelos Racionais. Os Modelos Clássicos são subdivididos em Modelos Clássicos Oportunistas e em Modelos Clássicos Partidários.

O primeiro estudo sobre possíveis relações entre políticas macroeconômicas e ciclos eleitorais foi apresentado no trabalho An Economic Theory of Political Action in a Democracy, de Anthony Downs, de 1957. Nesse trabalho, o autor busca determinar a relação entre policymakers (formuladores de políticas) e a sociedade, tendo como variável de controle a maximização do bem-estar social. Downs parte do pressuposto de que os políticos que possuem mais chances de sucesso de se elegerem ou de se reelegerem são aqueles que, em relação aos opositores, aumentariam o bem-estar da sociedade, especialmente com relação à renda dos indivíduos. Assim, a função definida para os partidos políticos que estão no poder compreenderia não só a formulação de políticas públicas de interesse coletivo, como também o atendimento das ambições individuais. 
Inspirado no estudo de Downs (1957), William Nordhaus introduziu como variante nessa abordagem o trade-off entre inflação e desemprego, presente na curva de Phillips. Tal estudo se tornou conhecido como a Teoria de Ciclos Políticos Eleitorais. Essa teoria é formada por duas correntes principais, sendo que ambas utilizam a curva de Phillips como principal instrumento de análise.

A primeira, proposta por Nordhaus (1975), e intitulada como Modelo Clássico Oportunista, é considerada como o trabalho seminal sobre a teoria de ciclos políticos eleitorais. Para o pesquisador, as flutuações econômicas, especialmente em períodos eleitorais, estão relacionadas a desvios da política econômica articulada por governantes em função do objetivo de vencer as eleições. $\mathrm{O}$ autor constatou que, no período anterior às eleições, o governante reduz a taxa de desemprego ao menor nível possível em detrimento dos altos custos inflacionários, consequência direta de políticas expansionistas, o que força o equilíbrio a um ponto inferior na curva de Phillips.

Em contrapartida, com o término das eleições, tal política é abandonada e a taxa de inflação reduzida, retomando o equilíbrio ao nível anterior das eleições. $\mathrm{O}$ objetivo seria o de sinalizar à sociedade a competência do governante como administrador. Nordhaus (1975) indica, ainda, que o nível de investimento dessas economias tende a ser subótimo, visto que ocorre mediante a diminuição do consumo que, por sua vez, é afetado pelo aumento da inflação.

Nordhaus (1975) parte da hipótese de que os partidos políticos não conseguem se diferenciar uns dos outros, e que todos eles almejam o poder e a vitória nas eleições. Outro ponto destacado é que a memória dos eleitores é praticamente nula no ato da eleição, fazendo com que o ciclo político se torne um evento em que os eleitores, sendo míopes ou ingênuos, não conseguem processar as informações de longo prazo disponíveis. A terceira e última hipótese descreve a capacidade precisa do governo de controlar a demanda agregada de forma a interferir no resultado econômico daquela sociedade.

A segunda corrente, conhecida como Modelo Clássico Partidário, tem como precursor o artigo de Douglas Hibbs, Political parties and macroeconomic policy, de 1977. A diferença da abordagem em relação a Nordhaus reside na presença de um componente ideológico na formulação de políticas econômicas. Em Hibbs (1977), a curva de Phillips (que ilustra o trade-off entre taxa de inflação e desemprego) é utilizada tal como em Nordhaus (1975), porém, ao contrário de seu predecessor, o autor sugere a existência de uma diferença ideológica entre os partidos políticos de esquerda e de direita. Ele argumenta que os partidos de esquerda são mais propensos a interferir na economia, dando prioridade a níveis menores de desemprego e, em consequência, a maiores níveis inflacionários. Em contrapartida, os partidos de direita voltam seus esforços para a manutenção da estabilidade financeira e o controle de preços, deixando o nível de emprego em segundo plano.

Os modelos de ciclos políticos desenvolvidos por Rogoff e Sibert (1988) e Rogoff (1990) podem ser considerados um avanço ao modelo proposto por Nor- 
dhaus (1975), por incorporar a hipótese de expectativas racionais e pela ampliação de temas, não se restringindo à taxa de desemprego e à inflação. No modelo teórico desses autores, o princípio básico é de que os ciclos políticos eleitorais surgem a partir da assimetria de informações. Eles assumem que o governo que está no poder consegue observar o feedback fornecido pela sociedade sobre uma determinada variável (impostos, moeda ou gastos do governo) antes mesmo que os próprios eleitores assimilem tal informação.

Deste modo, em períodos eleitorais, a manipulação dos indicadores faz com que a opinião popular acerca do governo, bem como sua reputação de competência, sejam positivas e, portanto, levem a um resultado favorável nas eleições. "Por exemplo, quanto menor a quantidade de impostos que o governo arrecadar e maior a quantidade de bens públicos que ele gerar, maior a impressão de competência entre a sociedade" (VIDEIRA, 2010, p. 16). Da mesma forma, ocorre também para os modelos de ciclos políticos eleitorais partidários com expectativas racionais, como é o caso do trabalho de Alesina (1989).

\subsection{Ciclos Políticos na Taxa de Câmbio}

Uma abordagem voltada para as relações externas de cada país deu origem ao modelo de Ciclos Políticos Racionais de Negócios, formulado por Strein e Streb (2004), em que as depreciações da taxa de câmbio atuam como um imposto sobre o consumo, sendo politicamente custosas. Para os autores, um governante incompetente e oportunista atrasa possíveis desvalorizações da moeda doméstica para depois das eleições, de forma a parecer competente para seu eleitorado, enquanto o gestor competente não distorce a taxa de câmbio.

De acordo com o modelo de Stein e Streb (2004), a necessidade do governo de aumentar a taxa de depreciação tem um calendário preciso, depois das eleições, haja vista que as desvalorizações incorrem em uma diminuição do poder de compra da população por bens importados, aumentando, assim, o seu grau de insatisfação com o governo. Desta forma, assumem que, no caso de uma economia aberta, a inflação é economicamente igual à desvalorização e que a racionalidade dos eleitores os faz questionar se as políticas adotadas no período eleitoral possuem um viés oportunista e, também, se o governante realmente faria uso de tal ferramenta.

Strein e Streb (2004) trabalharam com uma pequena economia aberta de dois períodos, com uma restrição cash-in-advance. Em síntese, os autores encontraram que, em uma configuração com informação assimétrica bidimensional com relação à competência e ao oportunismo, a taxa de depreciação da taxa de câmbio aumenta após as eleições no caso em que o grau de oportunismo dos candidatos políticos é suficientemente grande e generalizado.

Os resultados empíricos obtidos no trabalho dos autores para a América Latina comprovam a hipótese testada e indicam que a taxa de desvalorização é signi- 
ficativamente maior nos meses seguintes às eleições, em comparação com os meses anteriores. Em suma, o trabalho apresenta que, em meses que antecedem à eleição, as chances de a economia permanecer em um regime de câmbio apreciado são maiores do que nos meses que se sucedem à eleição. Desse modo, os produtos internacionais ficam mais baratos para o consumidor/eleitor na véspera de eleição, o que lhe dá a impressão de um nível de renda maior.

\section{Metodologia}

Como método de análise empírica foi escolhida a modelagem de dados em painel, devido à sua capacidade de apresentar dados nas dimensões de espaço e tempo, possibilitando uma melhor investigação sobre a dinâmica das mudanças na taxa de câmbio (WOOLDRIDGE, 2011). Esses modelos apresentam um comportamento mais complexo. Segundo Gujarati (2011), combinando uma análise ao longo do tempo com observações de corte transversal, é possível obter "dados mais informativos, maior variabilidade, menos colinearidade entre as variáveis, mais graus de liberdade e mais eficiência." (GUJARATI, 2011). Além disso, os modelos de dados em painel têm sido utilizados em muitos trabalhos sobre o tema, como nos seminais Alesina (1988) e Hibbs (1986), e também nos mais recentes, como Remmer (1993) e Cermeño, Grier e Grier (2010).

De acordo com o tipo de relação existente entre as variáveis adotadas na estimação, pode-se optar por três modelos de dados em painel: o de efeitos fixos, o de efeitos aleatórios e o modelo Pooled.

O modelo de dados empilhados, ou Pooled Data, ocorre quando se tem uma "série temporal de seções cruzadas", mas as observações em cada seção não se referem, necessariamente, à mesma unidade. Deste modo, faz-se o agrupamento de todas as observações da amostra, considerando as variáveis explicativas não estocásticas ou não relacionadas e, posteriormente, estimam-se os parâmetros por meio de Mínimos Quadrados Ordinários (MQO). Segundo Wooldridge (2011), o modelo de efeitos fixos (FE) pondera a existência de efeitos individuais dos países analisados, representando a heterogeneidade entre eles, capturando suas diferenças invariantes no tempo. Nesse modelo, os efeitos individuais podem ser correlacionados com as variáveis explicativas e é apresentado um intercepto para cada país.

No modelo de efeitos aleatórios (RE), assume-se que as variações entre os países são aleatórias e não correlacionadas com as variáveis explicativas. Assim, há um intercepto comum entre os países. Para Wooldridge (2011) e Greene (2012), os efeitos individuais não observados para cada país seriam dados por um termo aleatório $(\beta)$, e as variações entre os países seriam distribuídas aleatoriamente, sendo captadas pelo termo de erro que não se correlaciona com as variáveis explicativas. Portanto, o modelo RE pressupõe a autocorrelação constante, o que torna necessário realizar a estimação do modelo por mínimos quadrados generalizados (MQG), 
buscando corrigir o problema de correlação entre os termos de erro, como intuito de apresentar um estimador eficiente.

Os testes de especificação ${ }^{6}$ utilizados nos modelos propostos foram: (i) o Teste de Chow; (ii) o teste de Breusch-Pagan; e, por último, (iii) o teste de Hausman. Além disso, foi realizado o teste de diagnóstico de Wooldridge e o teste de Wald. Desse modo, caso seja detectado heterocedasticidade e autocorrelação serial, é necessário estimar o modelo empírico aplicando a correção de erros-padrão robustos ou bootstrap.

\subsection{Modelo empírico}

A hipótese testada no presente trabalho é a possível existência de ciclos políticos eleitorais sobre a média da taxa de câmbio visando captar a influência positiva ou negativa para o período de 1994 a 2016 nos países do Mercosul.

As variáveis utilizadas foram: taxa de câmbio real, dummies representativas do momento eleitoral (com valor 1 para ano eleitoral e 0 , caso contrário), grau de abertura da economia, taxa de juros dos Estados Unidos, tamanho de governo e termos de troca dos países analisados. Espera-se encontrar um valor negativo para a dummy representativa do momento eleitoral, para o grau de abertura no período eleitoral e para a taxa de juros internacional.

O primeiro modelo (Equação 1) contém 90 observações, sendo 18 períodos e seis variáveis para a estimação com uma dummy representativa do momento eleitoral para o Mercosul. O outro modelo (Equação 2), por sua vez, apresenta 90 observações, 18 períodos e nove variáveis para a estimação com as dummies representativas do momento eleitoral para cada país analisado. Desta forma, os modelos podem ser representados, respectivamente, da seguinte forma:

$$
\begin{aligned}
& R E R_{t}=\beta_{0}+\beta_{1} T T_{t}+\beta_{2} G A_{t}+\beta_{3} G O V_{t}+\beta_{4} T J U_{t}+\beta_{5} D \cdot M_{e r c o s u l}+u_{t} \\
& R E R_{t}=\beta_{0}+\beta_{1} T T_{t}+\beta_{2} G A_{t}+\beta_{3} G O V_{t}+\beta_{4} T J U_{t}+\beta_{5} D . \text { Argentina }_{t} \\
& +\beta_{5} \text { D. } \text { Brasil }_{t}+\beta_{5} \text { D. } \text { Paraguai }_{t}+\beta_{5} \text { D. } \text { Uruguai }_{t}+u_{t}
\end{aligned}
$$

Sendo que: $i=5$ países, $t=18$ anos, $R E R_{t}$ é a taxa de câmbio real efetiva, $\beta_{0}$ representa o termo constante (intercepto), $T T_{t}$ corresponde ao termo de troca, $G A_{t}$ é a abertura comercial, $G O V_{t}$ representa o tamanho do governo, $T J U_{t}$ corresponde à taxa de juros internacional, D.Mercosult é a variável dummy representativa do momento eleitoral no Mercosul, D.Argentinat, D.Brasil, D.Paraguai $t_{t}$ e D.Uruguai $t_{t}$ correspondem às variáveis dummies representativas do momento eleitoral em cada país membro do Mercosul, e $u_{t}$ é o termo de erro. A dummy da Venezuela será omitida para que não se tenha o problema de multicolinearidade.

6 Ver Gujarati (2011) e Greene (2012). 


\subsection{Descrição dos dados}

A definição das variáveis utilizadas para a estimação do modelo de análise se deu com base no trabalho de Goldfajn e Valdés (1999), adotado posteriormente por Bonomo e Terra (1999), Terra e Valladares (2010) e Oreiro et al. (2011). A periodicidade das variáveis utilizadas na estimativa dos modelos é anual e o período de investigação foi de 1997 a 2014.

\section{Taxa de câmbio efetiva real}

A série de taxa de câmbio efetiva real é obtida através da taxa de câmbio efetiva nominal (medida do valor de uma moeda doméstica em relação a uma média ponderada de várias moedas estrangeiras) dividida por um deflator de preços ou índice de custos. A efetividade dessa classificação está na utilização das inflações interna e externa para considerar uma média das taxas de câmbio entre um país e seus parceiros comerciais.

\section{Variável representativa do momento eleitoral}

Todos os países estudados seguem o regime presidencialista, sendo Brasil e Argentina com o tempo de mandato de quatro anos, com possibilidade de uma reeleição, e Paraguai e Uruguai com mandatos de cinco anos, com reeleição vetada. Por outro lado, a Venezuela apresenta mandato de seis anos, com possibilidade de reeleição por tempo indeterminado.

Alesina, Cohen e Roubini (1989) usaram, para representar o período eleitoral, uma variável dummy com valor 1 para o período correspondente a seis meses antes da eleição, e 0 em caso contrário. Em contrapartida, Bienen e Van de Walle (1991), que visam testar se ocorre uma depreciação cambial depois de realizadas as eleições, utilizaram a variável dummy com valor 1 para o mês das eleições e para os cinco meses seguintes, e 0 em caso contrário. Fialho (1997), em sua análise de ciclos eleitorais na economia brasileira, define a dummy "eleições" com o valor 1 no ano da eleição e 0 nos demais períodos. Portanto, o presente trabalho será baseado na classificação desse autor, devido à inexistência de dados mensais para algumas variáveis utilizadas.

As eleições presidenciais ocorreram nos seguintes anos: Argentina - 1999/2003/2007/2011; Brasil - 1998/2002/2006/2010/2014; Paraguai - 1998/2003/2008/2013; Uruguai - 1999/2004/2009/2014; Venezuela $1998 / 2000 / 2006 / 2012 / 2013$.

\section{Variáveis de controle}

i. Para Goldfajn e Valdés (1999), um dos determinantes da taxa de câmbio seria o grau de abertura da economia, visto que países que apresentam um maior nível de comércio internacional geralmente optam pela manutenção de uma taxa de câmbio fixa. A variável é definida como o grau de dependência do país quanto ao comércio externo e foi calculada através da soma das importações e exportações de cada país, dividida pelo seu respectivo PIB. 
ii. Outro determinante citado por Goldfajn e Valdés (1999) é a taxa de juros internacional, pois quanto menor ela é, maior será a apreciação cambial em curto prazo. Em longo prazo, conforme sugerem os autores, quanto menor a taxa de juros, menor a proporção de ativos financeiros internacionais e, desta forma, o déficit em transações correntes se eleva e se torna insustentável com o tempo.

iii. O tamanho do governo também é adotado como decisivo pelos autores supracitados para a definição do nível da taxa de câmbio adotada por cada país, já que uma expansão de gastos do governo, especialmente no sentido de provocar uma elevação da demanda de bens nontradeables superior à demanda desses bens pelo setor privado, pode ocasionar uma apreciação da taxa de câmbio real. Por outro lado, caso o governo aumente a sua demanda por bens importados, uma pressão pela depreciação cambial poderá ocorrer.

iv. Por último, os mesmos autores discorrem sobre os Termos de Troca e sua influência na taxa de câmbio, visto que a queda nessa variável proporciona um efeito renda negativo, reduzindo a renda real. Com essa queda, a demanda por bens nontradeables diminui e, para reequilibrar a economia, a taxa de câmbio deve se depreciar. Porém, nos termos de troca, ela pode gerar um efeito substituição, levando a um aumento na demanda por esses bens e, de modo oposto, apreciar a taxa de câmbio. $\mathrm{O}$ sinal esperado para a variável Termos de Troca depende da magnitude dos efeitos renda e substituição ocorridos em cada economia. Seu valor foi obtido através da divisão do valor das exportações nacionais pelo valor das importações do mesmo país.

\subsection{Fonte de dados}

A seguir são listadas as fontes dos dados utilizados:

Taxa de Câmbio Efetiva Real (RER) - dados mensais e anuais fornecidos pelo Fundo Monetário Internacional com base no dólar norte-americano (FMI, 2016).

Termos de Troca (TT) - dados anuais fornecidos pelo Fundo Monetário Internacional (FMI, 2016).

Grau de Abertura Comercial (GA) - construída utilizando os dados anuais de exportação e importação já fornecidos em proporção do PIB nacional, retirado da base de dados do Banco Mundial. (WB, 2016).

Tamanho do Governo (GOV) - dados referentes ao gasto corrente total de cada país. O proxy para essa variável foi extraído do banco de dados do Fundo Monetário Internacional (FMI, 2016).

Taxa de Juros Internacional (TJU) - taxa de juros dos Estados Unidos 3Month Treasury Bill. Fundo Monetário Internacional (FMI, 2016). 


\section{Resultados e discussão}

\subsection{Análise descritiva}

A análise descritiva da taxa de câmbio efetiva real para cada país estudado teve periodicidade mensal e apresenta a tendência dessa variável nos anos eleitorais. Nesta análise também será realizado um apanhado da situação econômica e cambial dos países nos anos de 1997 a 2014.

a) Argentina

A Argentina é o segundo maior país do Mercosul e se destaca pelo bom posicionamento em indicadores sociais e de renda na América do Sul. O país é classificado como emergente, seu histórico econômico recente é marcado por descontroles inflacionários e, atualmente, vive uma fase de austeridade fiscal visando conter os efeitos negativos de uma desaceleração do crescimento interno.

Os dados chamam a atenção pelo longo período da paridade do câmbio com o dólar (Currency Board), que se estendeu de 1991 a 2001. Durante esse período de ancoragem cambial com a moeda norte-americana, as taxas de inflação do país foram controladas e permaneceram próximas à zero. Além disso, a moeda doméstica manteve-se sobrevalorizada nessa ocasião. Em 2001, a paridade foi abandonada diante da crise que se instaurou no país. Essa crise causou uma forte desvalorização do peso argentino entre janeiro e junho de 2002, o que pode ser verificado na Figura 1 da série histórica apresentada abaixo.

A eleição, em 2003, de Nestor Kichner, apoiada pelo então presidente Eduardo Duhalde, coincide com uma leve depreciação cambial no mesmo período. Segundo o Informe Económico Trimestral, publicado pelo governo argentino, o ano de 2003 foi marcado por uma forte política de substituição de importações e saída de capitais estrangeiros do país devido, entre outros fatores, à renegociação da dívida externa argentina com o FMI.

Figura 1 - Evolução da taxa de câmbio efetiva real do peso argentino (ARS)

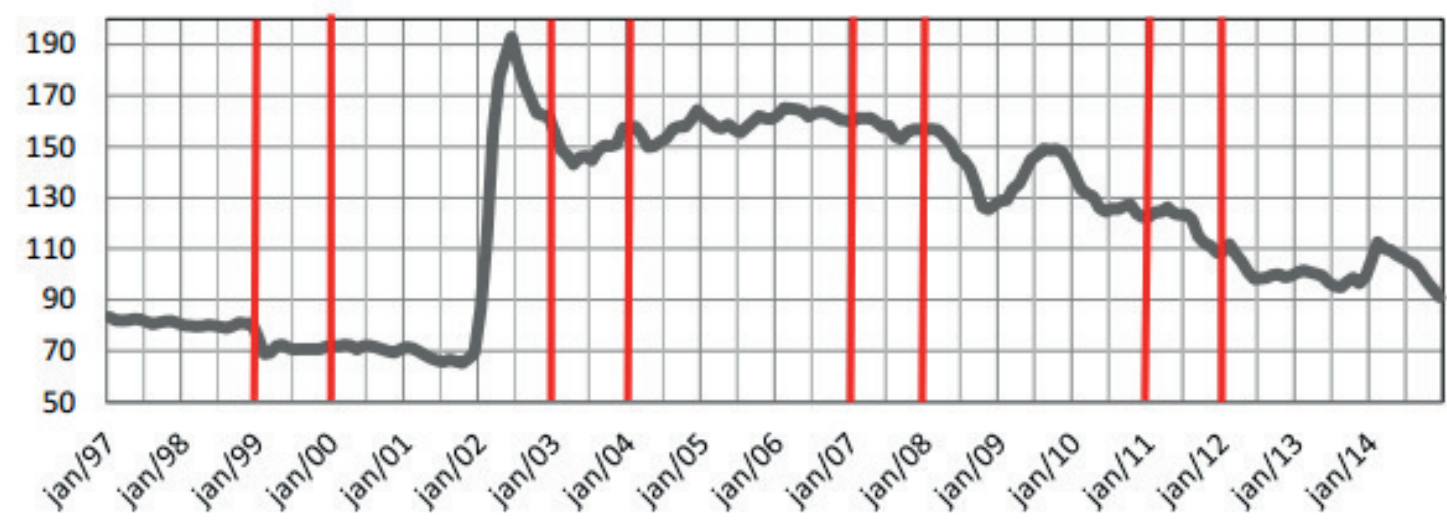

Fonte: Banco Central de la República Argentina (2016). Elaboração própria. 
Ademais, entre 2003 e 2007, verificou-se uma relativa estabilidade econômica, apesar da desvalorização da moeda. No ano de 2007, ocorreu o pleito eleitoral vencido pela então senadora Cristina Kirchner, apoiada pelo presidente anterior. Nesse mesmo ano, o câmbio apresentou uma tendência de leve apreciação, mesmo a moeda se mostrando desvalorizada em comparação com todo o período analisado. $\mathrm{O}$ país apresentou bons resultados econômicos, mas em detrimento de altas taxas de inflação. Em contrapartida, o peso argentino mostrou uma tendência de valorização entre 2009 e 2014, inclusive em 2011, ano de reeleição de Kichner.

A média e o desvio-padrão da variável Taxa de Câmbio Real para a moeda da Argentina foram, respectivamente, 119,68 e 34,36, sendo os maiores valores de todos os países do Mercosul analisados. O teste de média foi realizado e observou-se que as médias entre os períodos normais e os de eleição foram estatisticamente iguais.

\section{b) Brasil}

Segundo dados do $\mathrm{FMI}^{7}$, em 2015, a economia brasileira foi classificada como a nona maior do mundo medida pelo PIB nominal e sétima maior do mundo medida pelo PIB per capita. Na América do Sul, atua como forte influenciador no campo político e no econômico, principalmente após o estreitamento das relações diplomáticas do país com seus vizinhos, ocorrido a partir do primeiro Governo Lula, em 2002.

Com relação à taxa de câmbio real brasileira entre 1994 e 1999, o câmbio brasileiro foi mantido fixo visando ao controle da inflação via ancoragem cambial. Em 1999, sofreu uma desvalorização devido à troca do regime cambial fixo para o flutuante. Nesse período, o Brasil se encontrava em um momento de perdas de reservas internacionais e de ataques especulativos decorrentes de sua situação macroeconômica. O Banco Central do Brasil utilizou como justificativa para a utilização de políticas de intervenção cambial os sistemáticos déficits da conta corrente nacional desde meados da década de 1990.

A eleição, em 2002, de Luiz Inácio da Silva, de oposição ao governo da época, foi marcada por uma acentuada valorização do real. A tendência foi invertida a partir do primeiro mês de 2003. O período foi caracterizado como um período de alta, conforme afirmaram Prates, Cunha e Lélis (2008), que se estendeu até o ano de 2007. A retomada da liquidez atraiu fluxos de capital para o Brasil, que serviu de gancho para a valorização cambial, somada a um cenário favorável no comércio internacional.

7 FMI, World Economic Outlook Data base 2016. 
Figura 2 - Evolução da taxa de câmbio efetiva real do Real (BRL)

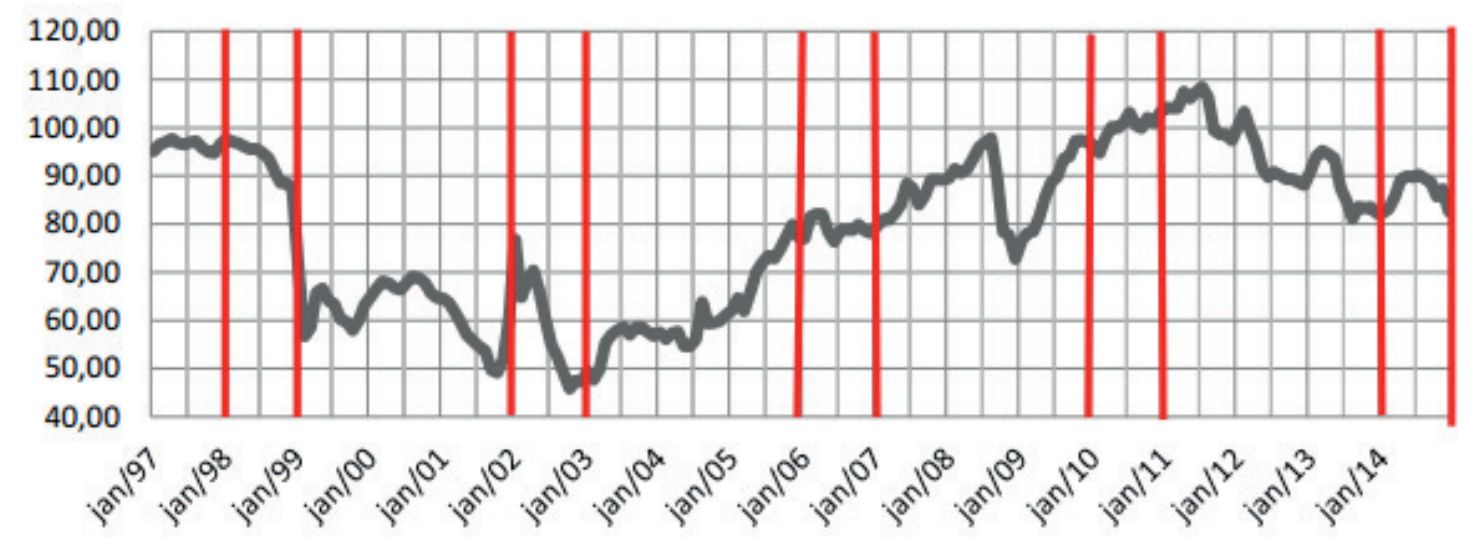

Fonte: Fundo Monetário Internacional (2016). Elaboração própria.

Em 2006, ocorreu a reeleição do presidente Lula, não tendo sido possível verificar variações significativas em relação ao câmbio médio do período. A crise financeira internacional em 2008 contribuiu significativamente para o retorno da desvalorização cambial, ocasionada principalmente pelo período de interrupção dos fluxos internacionais. Nesse mesmo período, a taxa de juros foi utilizada para reverter o cenário de crise, gerando uma forte entrada de ativos estrangeiros no país.

Em 2010, Dilma Rousseff foi eleita presidente, contando com o apoio de seu sucessor. A análise do gráfico permite inferir que ocorreu uma alteração nos padrões até então estabelecidos e o ano foi marcado por depreciações da taxa de câmbio. Tal tendência se manteve até meados de 2011, com algumas apreciações pontuais. Em contrapartida, 2013 foi marcado pelo início de uma crise política que se perpetua até os dias atuais, aumentando o grau de incerteza dos agentes econômicos e causando, consequentemente, depreciações na taxa de câmbio. Por fim, em 2014, ocorreu a reeleição da presidente Dilma, sendo o ano marcado por uma desvalorização do real no primeiro período e valorização no segundo.

A média e o desvio-padrão da variável Taxa de Câmbio Real para a moeda brasileira foram, respectivamente, 79,55 e 15,80. O teste de média foi realizado e observou-se que as médias entre os períodos normais e os de eleição foram estatisticamente diferentes, assim, pode-se entender que ocorreu um movimento cambial nos períodos eleitorais.

c) Paraguai

O Paraguai, diferentemente dos demais países da América do Sul, apresenta uma baixa taxa de inflação histórica, com uma média de 5\% a.a. Apresentou um crescimento surpreendente nas primeiras décadas do século XXI, mesmo com sua economia fortemente baseada em produtos primários.

O país manteve o regime de flutuação administrada de 1989 até o início da década de 2000. Entretanto, os "níveis" de regulação variaram ao longo desse período. 
Em 1998, não ocorreu variação significativa na média do peso paraguaio e a moeda se manteve estável, coincidindo com a eleição do presidente Raúl Cubas Grau. Logo em seguida, o ano posterior ao pleito foi marcado por uma acentuada valorização logo nos seus primeiros meses. Em 2003, também ano de eleição presidencial, é possível estabelecer uma linha de tendência para a taxa de câmbio que indica uma depreciação dela, mesmo que pequena.

Figura 3 - Evolução da taxa de câmbio efetiva real do Guarani Paraguayo (PYG)

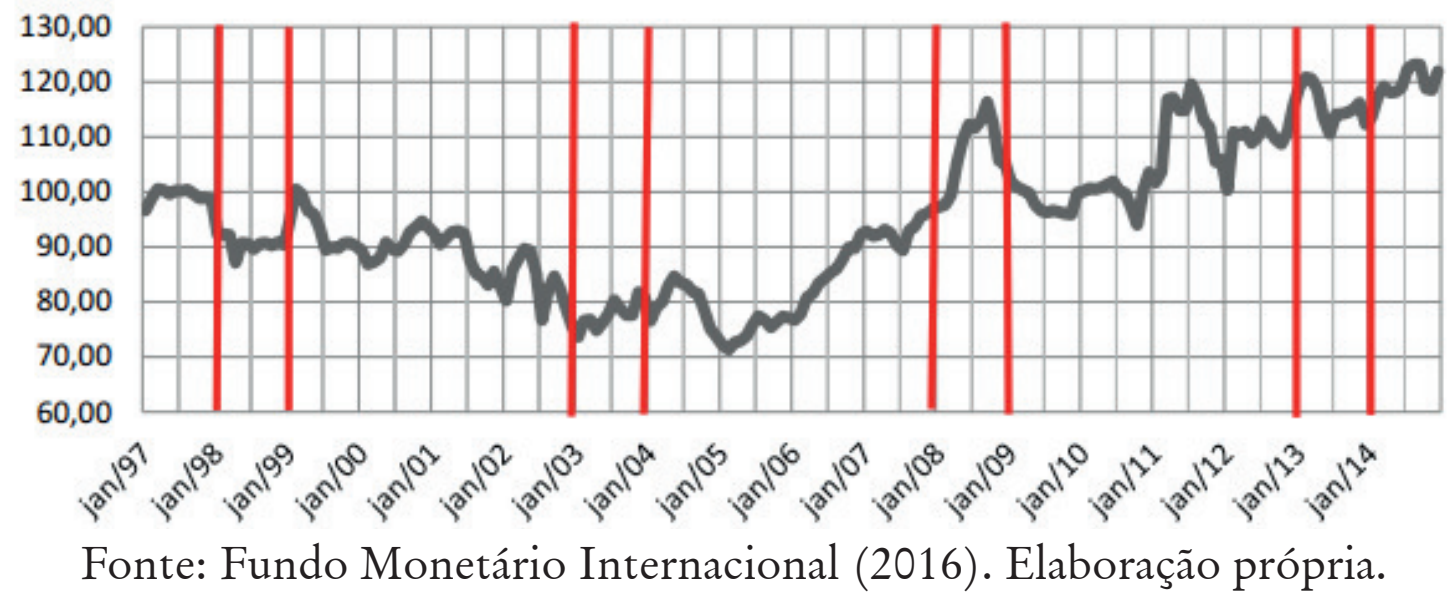

A crise econômica mundial de 2008, ano de eleição de Fernando Lugo, acentuou a tendência de depreciação cambial que já vinha ocorrendo desde 2005. A crise política do país, em 2012, aparentemente não resultou em grandes oscilações na moeda. Em abril de 2013, o atual presidente paraguaio, Horacio Cartes, venceu as eleições gerais. $\mathrm{O}$ mês coincide com o ponto de inflexão no processo de desvalorização da moeda. O Paraguai não sofreu bruscas mudanças em seus regimes cambiais ao longo do período de análise aqui proposto, permanecendo com um regime de flutuação administrada até 2014.

A média e o desvio-padrão da variável Taxa de Câmbio Real para a moeda paraguaia foram, respectivamente, 95,47 e 12,90. O teste de média foi realizado e observou-se que as médias entre os períodos normais e os de eleição foram estatisticamente diferentes, assim como o caso brasileiro.

d) Uruguai

O Uruguai caracteriza-se como uma economia pequena, porém considerada aberta, e os bens transacionáveis representam, em média, 50\% da cesta doméstica de bens do país. Além disso, sua economia é altamente dolarizada. 
Figura 4 - Evolução da taxa de câmbio efetiva real do peso uruguaio (UYU)

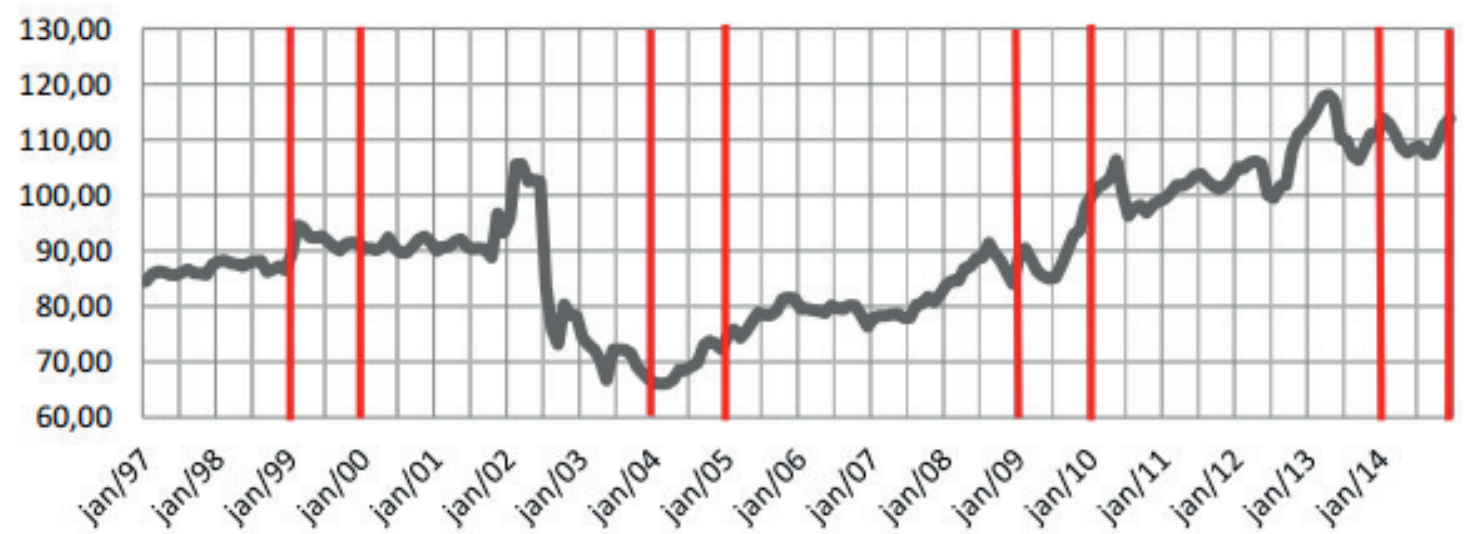

Fonte: Fundo Monetário Internacional (2016). Elaboração própria.

Em 2002, abandonou o regime de bandas cambiais devido ao impacto da crise argentina em sua economia, adotando um regime de flutuação administrada. $\mathrm{O}$ resultado gerou uma significativa valorização do peso uruguaio, entretanto, já no segundo semestre desse mesmo ano, a moeda voltou a se desvalorizar, mas manteve a tendência de queda da taxa de câmbio efetiva real. A eleição de 2004 foi acompanhada de uma depreciação do câmbio em todo o ano. Logo em 2006, a taxa de câmbio se mostrou estável quanto a esse quesito. Em 2009, José Mujica foi eleito presidente e o período de pleito apresentou uma depreciação cambial, seguindo a tendência iniciada ainda em 2007. Por fim, em 2014, o guarani sofreu uma valorização no período, mas manteve-se estável na média do ano.

A média e o desvio-padrão da variável Taxa de Câmbio Real para a moeda do Uruguai foram, respectivamente, 90,05 e 11,94, sendo essa moeda com o menor desvio-padrão dentre as moedas do Mercosul analisadas. $\mathrm{O}$ teste de média foi realizado e observou-se que as médias entre os períodos normais e os de eleição foram estatisticamente iguais.

e) Venezuela

A Venezuela possui sua economia historicamente baseada em commodities. Antes da descoberta de suas reservas de petróleo, destacava-se na produção de cacau e café. A partir do século XX, o petróleo dominou sua matriz econômica e foi responsável pelo rápido crescimento de seu produto interno, porém também desencadeou uma séria crise na dívida externa do país e a deterioração do poder de compra da população.

O país adotou o regime de bandas cambiais a partir de 1996 e tem sua economia fortemente atrelada à exportação de petróleo. A eleição de Hugo Chávez, em 1998, foi marcada por uma desvalorização da moeda em todo o ano. A recessão ocorrida em 1999 contribuiu para a deterioração da economia e fortaleceu a tendência de desvalorização do Bolívar. A partir de 2001, com um aumento do preço do petróleo, o país viveu uma retomada no crescimento e, em 2003, adotou um regime de câmbio fixo, com maior rigidez no controle de capitais estrangeiros. 
Figura 5 - Evolução da taxa de câmbio efetiva real do bolívar venezuelano (VEF)

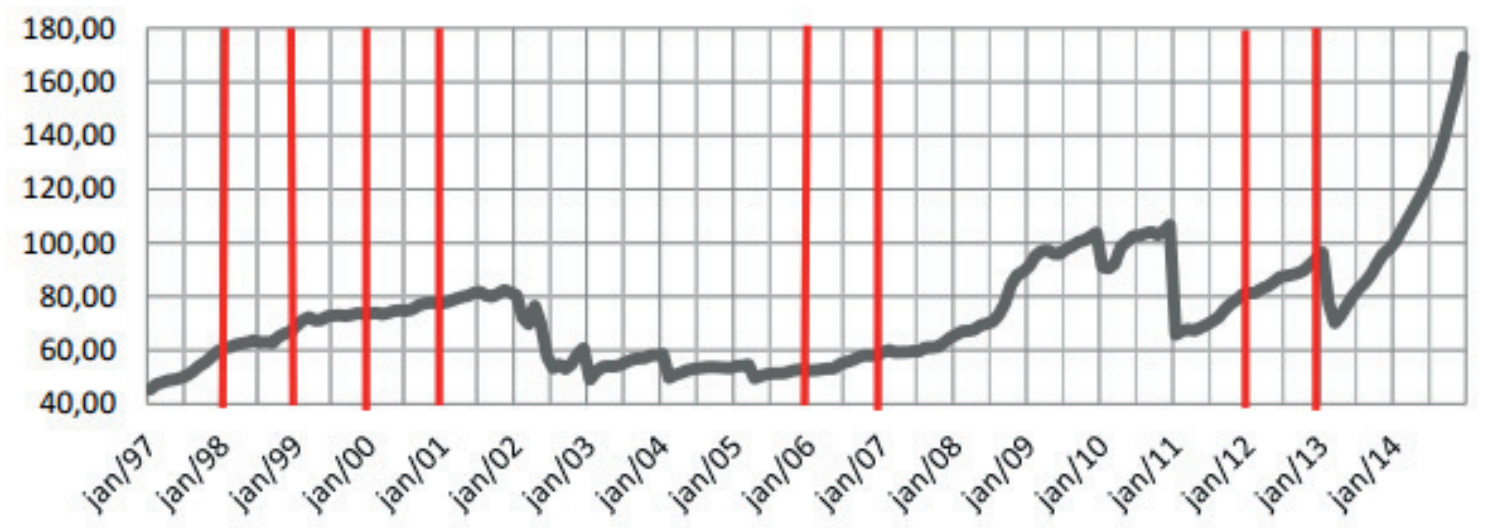

Fonte: Fundo Monetário Internacional (2016). Elaboração Própria.

Em 2006, ocorreu a reeleição de Chávez, e pode-se observar o início de uma depreciação cambial que se estendeu até 2010. Já em 2009, para controlar os efeitos da crise, todo o esforço do governo foi no intuito de controlar a inflação. " $E m$ janeiro de 2010, o regime cambial da Venezuela foi alterado, sendo adotado um câmbio diferencial, com suas taxas fixas (uma menor, para bens considerados prioritários, $e$ outra maior) e uma taxa flutuante (para pagamento da dívida pública)." (Bondar, 2010, p.16). No final desse ano, tal regime foi alterado, sendo adotado um câmbio diferencial, eliminando a taxa preferencial. Foi estabelecida a manutenção de uma única taxa fixa, a de 4,30 bolívares por dólar. O pleito eleitoral de 2012, que culminou em uma nova reeleição de Hugo Chávez, apresentou desvalorização do bolívar em todo o ano, seguida de uma apreciação cambial nos primeiros meses de 2013. A mudança de regimes cambiais tem sido constante no país nos últimos anos. Assim, a inferência sobre os níveis da taxa de câmbio deve levar em consideração tais políticas e não somente a flutuação do mercado.

A média e o desvio-padrão da variável Taxa de Câmbio Real para a moeda venezuelana foram, respectivamente, 73,67 e 19,82, sendo essa a menor média dentre os países do Mercosul analisados. O teste de média foi realizado e observou-se que as médias entre os períodos normais e os de eleição foram estatisticamente diferentes, assim, pode-se entender que ocorreu um movimento cambial nos períodos eleitorais.

De maneira geral, ao analisar a conjuntura exposta até aqui, verificou-se que, na grande maioria dos anos eleitorais, a variação média da taxa de câmbio segue uma tendência de depreciação. Além disso, a escolha dos regimes cambiais afeta diretamente o comportamento dessas moedas, principalmente quando se praticam regimes cambiais fixos ou de banda. Outro fator relevante é o cenário internacional, que influencia de forma significativa o desempenho dessas economias, tidas como exportadoras.

\subsection{Análise dos resultados estatísticos}

A análise econométrica das regressões realizadas por dados em painel são 
114 C. S. Teles; J. H. Alves; S. W. D'Amato - A taxa de câmbio no Mercosul: uma análse...

realizadas a seguir, bem como a discussão dos resultados encontrados para o Mercosul e para os países no período analisado.

a) O Mercosul

Para a regressão com a variável representativa do momento eleitoral para o Mercosul, definiu-se que, com base nos testes de Chow, Breusch-Pagan e Hausman, o modelo de efeitos fixos é o que melhor satisfaz as condições necessárias para estimação. O teste de Wald, para detecção de heterocedasticidade em grupo, rejeitou a hipótese de erros homocedásticos, bem como o teste de Wooldridge indicou a presença de autocorrelação . Assim, julga-se necessária a estimação do modelo de efeitos fixos por erros-padrão robusto:

Tabela 1 - Modelo de determinação da taxa de câmbio efetiva no Mercosul para o período de 1997 a 2014

Variável dependente: Taxa de câmbio -- Método de estimação: Fixed - effects regression

\begin{tabular}{c|c}
\hline Variáveis Independentes & Coeficientes \\
\hline Grau de Abertura Comercial & 20,605 \\
Taxa de Juros dos EUA & $(0,826)$ \\
Termos de Troca & $-1,517$ \\
& $(0,061)^{*}$ \\
Tamanho do Governo & 0,100 \\
& $(0,228)$ \\
D. Mercosul & 0,150 \\
& $(0,762)$ \\
Constante & 2,962 \\
& $(0,019)^{* *}$ \\
Observações & 53,450 \\
\hline
\end{tabular}

Nota: *** Significante a $1 \%$; * Significante a 5\%; * Significante a 10\%. O número entre parênteses é o p-valor. Fonte: Elaboração própria.

Com relação a tais resultados, são sugeridas interpretações gerais: algumas das variáveis de controle utilizadas apresentaram os sinais esperados, porém somente o coeficiente da taxa de juros norte-americana mostrou-se significativa e com impacto negativo no valor do câmbio do Mercosul no período.

8 Os resultados dos testes de diagnóstico e de especificação serão apresentados na Tabela 1A do Apêndice. 
Tais resultados vão de encontro aos sugeridos por Videira (2010) e Huang e Terra (2016), que justificam que a taxa de juros internacional influencia a taxa de câmbio real de duas maneiras. A princípio, uma maior taxa de juros internacional aumenta a saída de capitais, resultando em depreciação da taxa de câmbio no curto prazo. No longo prazo, no entanto, uma maior taxa de juros internacional é seguida por um maior estoque de ativos externos líquidos.

Portanto, economias com ativos externos líquidos relativamente mais elevados podem apresentar um déficit insustentável em conta corrente. $\mathrm{O}$ oposto ocorre nos países que tiveram suas moedas desvalorizadas, visto que uma melhora nas suas exportações, puxada pelo câmbio, gera uma nova entrada de moeda estrangeira no país.

Ainda sobre as variáveis de controle, cabe aqui ressaltar que mesmo não apresentando coeficientes estatisticamente significativos para a determinação da RER, é possível inferirmos através da análise da variável Tamanho do Governo que os incumbentes possivelmente dedicam uma parcela maior dos gastos públicos a bens não comercializáveis, como indicado por Goldfajn e Valdés (1999). Sugere-se, ainda, que um dos motivos para a não significância da variável no modelo seria uma inferência do governo na RER através de uma mudança na composição das despesas, o que não é captado pela variável utilizada neste trabalho.

O coeficiente da variável representativa do momento eleitoral D. Mercosul, responsável pela detecção de ciclos políticos no bloco econômico no período analisado, apresentou coeficiente estatisticamente significativo e positivo, indicando uma depreciação cambial em, ao menos, um dos períodos eleitorais analisados. Tal resultado pode sugerir que, de forma geral, ocorreram interferências na taxa de câmbio, porém contrárias às supostas na literatura de Ciclos Políticos.

b) Países do Mercosul

Assim como a regressão estimada para o Mercosul, o modelo com dummies representativas do momento eleitoral de cada país (Argentina, Brasil, Paraguai, Uruguai e Venezuela) também indicou a necessidade de um modelo de efeitos fixos, apresentando ausência de homocedasticidade e presença de correlação, como indicado na Tabela 2A (Apêndice). Para a correção dos erros indicados pelos testes expostos na Tabela 2A, foi utilizado o método de bootstrap. Os resultados obtidos são expostos na Tabela 2, a seguir. 
Tabela 2 - Modelo de determinação da taxa de câmbio efetiva nos países do Mercosul para o período de 1997 a 2014

\begin{tabular}{|c|c|}
\hline Variável dependente: taxa de câmbio. Método de estimação: Fixed - effects regression \\
\hline Variáveis Independentes & Coeficientes \\
\hline Grau de Abertura Comercial & 15,285 \\
Taxa de Juros dos EUA & $(0,001)^{* * *}$ \\
Termos de Troca & $-2,509$ \\
& $(0,000)^{* * * *}$ \\
Tamanho do Governo & 0,0281 \\
& $(0,474)$ \\
D. Argentina & $-0,368$ \\
& $(0,324)$ \\
D. Brasil & 5,450 \\
& $(0,000)^{* * *}$ \\
D. Paraguai & 5,803 \\
& $(0,000)^{* * * *}$ \\
D. Uruguai & 2,079 \\
& $(0,018)^{* *}$ \\
Constante (Venezuela) & 3,542 \\
& $(0,018)^{* *}$ \\
RHO & 52,067 \\
R 2 & $(0,000)^{* * * *}$ \\
Observações & \\
& 0,692 \\
& 90 \\
\hline
\end{tabular}

Nota: *** Significante a $1 \%$; ** Significante a5\%; * Significante a10\%. O número entre parênteses é o p- valor. Fonte: Elaboração própria.

O coeficiente da variável Grau de Abertura apresentou resultado positivo e estatisticamente significante nesta análise, o que leva à interpretação de que uma expansão nas transações comerciais de cada país promove uma depreciação da taxa de câmbio. Além do mais, seu coeficiente mostrou-se relativamente alto, caracterizando uma forte participação na determinação da taxa de câmbio. Portanto, essa ideia está em acordo com a teoria econômica internacional, que apresenta a taxa de câmbio abaixo do praticado em mercados imperfeitos quando ocorre um livre fluxo de capitais entre os países.

A variável da Taxa de Juros Norte-Americana mostrou-se significativa e com impacto negativo, assim como na análise realizada para o Mercosul. Em contraparti- 
da, as variáveis Tamanho do Governo e Termos de Troca não se mostram significativas para o estudo, porém os sinais apresentados podem inferir que ambas impactam negativamente na apreciação do câmbio. A literatura indica que uma melhora nos termos de troca de um país reflete um aumento das exportações líquidas, que pode ser ocasionado por choques negativos na renda, desvalorizando a moeda doméstica diante das moedas estrangeiras.

Em concordância com os coeficientes obtidos na estimação anterior, foram encontrados resultados positivos para dummies eleitorais por países. Em todos os cinco países ocorreram depreciações na RER, em pelo menos um ano eleitoral. Resultado semelhante foi achado por Remmer (1993), cujo trabalho para alguns países da América Latina indica sistemáticas desvalorizações nas taxas de câmbio reais nos períodos de pré-eleição e eleição.

O trabalho de Huang e Terra (2016) para a América Latina e para o Leste Asiático apresentam resultados opostos para as duas regiões. Na América Latina, os autores observaram um padrão semelhante ao proposto pela Teoria de Ciclos Políticos aplicada à taxa de câmbio, ou seja, em períodos pré-eleitorais, a tendência é de valorização da moeda e, nos pós-eleitorais, de desvalorização.

Já para o Leste Asiático ocorre exatamente o contrário. A taxa de câmbio tende a permanecer depreciada nos períodos pré-eleitorais e, após as eleições, apreciada. A explicação proposta por Huang e Terra (2016) diz respeito à matriz econômica de cada região. Os autores expõem que as economias asiáticas possuem um setor de bens comercializáveis maior e, consequentemente, mais eleitores priorizariam um bom desempenho deste em detrimento do setor de bens não comercializáveis.

Para os países latino-americanos, os autores apresentam que os eleitores estariam mais interessados em uma melhora no setor de bens não comercializáveis 9 Portanto, visando maximizar seus votos, o gestor focaria suas medidas no maior grupo de eleitores. Além disso, consideram que o eleitorado é míope e que não consegue obter todas as informações disponíveis, diferentemente do candidato ao governo.

Dados os países, nesse período de tempo, com as variáveis utilizadas neste trabalho, aliado ao fato de que as economias aqui discutidas são primordialmente exportadoras, o ciclo encontrado pode estar em desalinho com a teoria adotada. Justifica-se tal comportamento com base na dinâmica da balança comercial dos países do Mercosul, sendo estes exportadores líquidos e, assim, induzindo os seus governantes a beneficiarem tal setor em suas medidas para angariar votos através da depreciação cambial.

9 São considerados comercializáveis os alimentos industrializados e semielaborados, artigos de limpeza, higiene e beleza, mobiliário, utensílios domésticos, equipamentos eletroeletrônicos, veículos, álcool, combustível, artigos de cama, mesa, banho, fumo e bebidas, vestuário e material escolar. O conjunto de preços de itens não comercializáveis inclui produtos in natura, alimentação fora do domicílio, aluguel, habitação, despesas operacionais, seguro, reparos, lavagem e estacionamento de veículos, recreação e cultura, matrícula e mensalidade escolar, livros didáticos, serviços médicos e serviços pessoais. 
Além disso, a incerteza política que se instaura, principalmente em países emergentes, durante períodos eleitorais, tende a ser significativa e impacta diretamente nos níveis de preço das respectivas moedas locais. Assim, a importância de uma balança comercial superavitária vai além dos resultados contábeis. Há, de fato, um peso de caráter político e social por tais fatores, e uma melhora dessa situação agiria em favor da aprovação do governo no poder. A relação taxa de câmbio e balança comercial é imprescindível e não deve ser desconsiderada.

Outro fator importante a ser pontuado corresponde à evolução dos governos ditos de esquerda nesses países no período recente, como aponta o relatório Estudos Econômicos para a América Latina e Caribe de 2012-2013 e 2014, elaborado pela Comissão Econômica para a América Latina e o Caribe (CEPAL). Ainda segundo o documento, os regimes democráticos ali instaurados são relativamente novos, estando esses países em processo de amadurecimento e consolidação das suas bases institucionais.

\section{Conclusão}

A taxa de câmbio representa um componente essencial para países que desejam obter bons resultados no comércio internacional e sua análise é imprescindível quando se trata de blocos econômicos. O Mercosul se consolidou com parte ativa das dinâmicas comerciais na América do Sul e vem alcançando, de forma gradual, os objetivos propostos em sua criação. A integração dos países membros e associados pode ser verificada ao se analisar o fluxo comercial entre esses países e como apresentam uma tendência de alta no período recente.

Aplicada a esse cenário, a teoria de ciclos políticos, voltada às taxas de câmbio, traz alguns pressupostos sobre os fatores que a determinam. De forma geral, esperava-se encontrar evidências de manipulações nas políticas cambiais nos períodos pré-eleitorais, em que uma apreciação da moeda doméstica no momento anterior às eleições agiria como maximizador de votos para o candidato ao governo ou seu sucessor. O contrário ocorreria no período posterior, visando ao retorno da taxa de câmbio para o seu nível de equilíbrio.

Portanto, procurou-se verificar o impacto das eleições presidenciais dos países membros do Mercosul no nível de suas respectivas taxas de câmbio nos anos de 1997 a 2014. Através da estimação em dados em painel por modelo de efeitos fixos, os resultados demonstraram que, diferentemente da teoria adotada, em períodos pré-eleitorais a tendência, tanto no bloco quanto nos países, é de depreciação cambial. São encontradas, na literatura, evidências empíricas alinhadas com este estudo, como é o caso de Remmer (1993), que, em seu trabalho, justifica que, nos países da América Latina, as interferências na economia tendem a ocorrer no período pós -eleitoral, ou seja, no período pré-eleitoral não há manipulação direta da variável, mas, sim, o adiamento de correções, provavelmente devido à impopularidade dessas 
medidas. E ainda Huang e Terra (2016), em sua análise para a Ásia, também encontram evidências de depreciação cambial antes das eleições.

As análises descritivas da evolução da taxa de câmbio efetiva real foram ao encontro dos resultados encontrados na estimação por painel, segundo os quais, na maioria dos períodos pré-eleitorais, a taxa de câmbio desvalorizou-se. A breve contextualização do cenário político e social recente também apontou possíveis fatores exógenos aos adotados neste trabalho para a determinação das políticas cambiais. A mudança de regime cambial fez-se presente em vários momentos do período analisado, além das crises externas e internas de cada país.

É necessário salientar ainda que tais resultados podem estar relacionados à estimação do modelo utilizado. Com relação ao período adotado para a variável representativa do momento eleitoral, esta foi inserida para captar os efeitos no ano eleitoral, não conseguindo separar o exato ponto de inflexão da série, que corresponderia ao mês do pleito. Além disso, sabe-se que efeitos de curto prazo podem ter se dissipado ao longo do ano, o que pode ter acontecido com as relações entre a taxa de câmbio e as variáveis de controle, impossibilitando uma análise mais precisa de impactos imediatos.

Outro ponto a ser analisado e incluído em estudos posteriores diz respeito ao grau de confiabilidade do mercado nos governos vigentes e à incerteza que se instaura nos momentos eleitorais. O Emerging Markets Bond Index (EMBI+) é um índice baseado em títulos da dívida emitidos por cada país e é um indicador do risco de investimento destes. É comumente utilizado como proxy para esse tipo de variável.

Os resultados encontrados contribuem para que se possa melhor compreender a Teoria dos Ciclos Políticos e como ela atua em diferentes regiões de acordo com suas características . esta não é, portanto, uma discussão esgotada. A Teoria de Ciclos Políticos Eleitorais é recente e sua literatura ainda não foi capaz de consolidar as pressuposições que o modelo levanta. Portanto, trabalhos posteriores que analisem com mais precisão os momentos eleitorais se fazem necessários.

\section{Referências bibliográficas}

ALESINA A, COHEN G, ROUBINI N. Electoral business cycles in industrial democracies. European Journal of Political Economy. v.23:1-25, 1989.

ALESINA, A.; ROUBINI, N. Political cycles in OECD economies. Review of Economic Studies, v. 59, n. 4, p. 663-688, 1992. crossref https://doi. org/10.2307/2297992

ALESINA, A., SACHS, J. Political parties and the business cycle in the United States, 1948-1984. Journal of Money, Credit and Banking 20, 1988. cross ref $\underline{\text { https://doi.org/10.2307/1992667 }}$ 
ALIYEV. Ruslan. Determinants of the Choice of Exchange Rate Regime in Resource- Rich Countries. Working Paper Series [S.l: s.n.], 2014. Disponível em: <https://www.cerge-ei.cz/pdf/wp/Wp527. pdf $>.9788073433437$.

BARROS, DANIEL. Volatilidade cambial: um obstáculo à coordenação de políticas macroeconômicas no Mercosul. A Economia em Revista v.17 No.1, 2009.

BERDIEV, Aziz N.; KIM, Yoonbai; CHANG, Chun Ping. The political economy of exchange rate regimes in developed and developing countries. European Journal of Political Economy v. 28, p. 38-53, 2012. crossref https://doi.org/10.1016/j. ejpoleco.2011.06.007

BIENEN, Henry e VAN DE WALLE, Nicolas. Of time and power: leadership duration in the modern world.Stanford, Standord University Press, 1991.

BLOMBERG, S.Brock; HESS, Gregory D. Politics and exchange rate forecasts. Journal of International Economics v. 43, n. 1-2, p. 189-205, 1997. crossref https:// doi.org/10.1016/S0022-1996(96)01466-3

BONDAR, C. Unificação monetária no Mercosul: uma aplicação da teoria das áreas monetárias ótimas utilizando a metodologia VAR. Porto Alegre, 2010 - Disponível em: < $\quad$ http://www.lume.ufrgs.br/bitstream/handle/10183/28168/000765920. pdf? sequence $=1>$

BONOMO, M.; TERRA, C. The political economy of exchange rate policy in Brazil: 1964-1997. Research Department Publications. Inter-American Development Bank, Research Department, 1999.

CERMEÑO, Rodolfo; GRIER, Robin; GRIER, Kevin. Elections, exchange rates and reform in Latin America. Journal of Development Economics v. 92, n. 2, p. 166-174 , 2010. crossref https://doi.org/10.1016/j.jdeveco.2009.03.002

DOWNS, A. An Economic Theory of Political Action in a Democracy, Harper and Row, New York. 1957.

ESTUDO ECONÔMICO DA AMÉRICA LATINA E DO CARIBE: Três décadas de crescimento desigual e instável. Comissão Econômica para a América Latina e o Caribe (CEPAL). Anual. Agosto de 2013.

FIALHO, T. M. Testando a Evidência de Ciclos Políticos no Brasil. Revista Brasileira de Economia, Vol.51, no. 3, pp. 379-389. 1997. 
FIALHO, T. M. Ciclos Políticos: uma resenha. Revista de Economia Política, 19(2):131-49. 1999.

FRIEDEN, Jeffry A.; STEIN, Ernesto. The political economy of exchange rate policy in latin america: an analytical overview. The Currency Game: Exchange Rate Politics in Latin America. [S.l: s.n.], 2001. p. 1-19. 1886938873.

FROYEN, R. T. Macroeconomia: teorias e aplicações. Ed. 2. - São Paulo: Saraiva, 2013.

FUNDO MONTÁRIO INTERNACIONAL - WORLD ECONOMIC OUTLOOK DATA BASE. Disponível em https://www.imf.org/external/pubs/ft/ weo/2015/02/weodata/index.aspx. Acesso em Agosto de 2016.

GOLDFAJN, I., VALDÉS, R. The aftermath of appreciations. The Quarterly Journal of Economics Vol.114, pp. 229-262. 1999. crossref https://doi. org/10.1162/003355399555990

GREENE, H., Econometric Analysis. Stern School of Business, New York University. Ed. 7. 2012

GUJARATI, Damodar N. Econometria Básica. Ed. 5. 2011.

HIBBS, D. "Political Parties and Macroeconomic Policy," American Political Science Review 71, 1467-87, 1977. crossref https://doi.org/10.1017/ $\underline{\mathrm{S} 0003055400269712}$

. Political parties and macroeconomic policies and outcomes in the United States. American Economic Review Papers and Proceedings, v. 76, n. 2, p. 66-70, 1986.

HUANG, Sainan; TERRA, Cristina. Electoral Exchange Rate Cycle: East Asia vs. Latin America. Economics \& Politics n. 71403295 , 2016.

INFORME MERCOSUL No 19 (2013-2014) Segundo Semestre 2013, Nov. 2014 - Disponível em https://publications.iadb.org/handle/11319/6704.

LEBLANG, D. E BERNHARD, W. Parliamentary Politics and Foreign Exchange Markets: The World According to GARCH. International Studies Quarterly, 50: 69-92, (2006). crossref https://doi.org/10.1111/j.1468-2478.2006.00393.x

LOBO, B.J.; TUFTE, E. Exchange Rate Volatility: Does Politics Matter?. Journal of Macroeconomics, $\quad$ v. $20, \quad$ n. $\quad 2, \quad$ p. $\quad 3 \quad 5 \quad 1-$ 365, mar.1998. Disponível em: <http://linkinghub.elsevier.com/retrieve/pii/ S0164070498000627>. Acesso em: 17 jun. 2016. 
NORDHAUS, W. The Political Business Cycle. Review of Economic Studies, Vol. 42 (2), pp. 169-90, (1975). crossref https://doi.org/10.2307/2296528 OREIRO, J. L., PUNZO, L., ARAUJO, E.,SQUEFF, G. Taxa real de câmbio, desalinhamento cambial e crescimento econômico no Brasil (1994-2007). Revista de Economia Política, vol. 31, no 4 (124), pp. 551-562, outubro-dezembro/2011.

PRATES, Daniela Magalhães et al. O Brasil e a crise financeira global: avaliando os canais de transmissão nas contas externas. Revista de Economia Contemporânea, 2011.

REMMER, K. The Political Economy of Elections in Latin America, 19801991. The American Political Science Review. 87(2): 393-407. (1993)

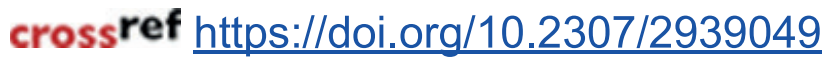

RODRIGUEZ, Cesar M. Economic and political determinants of exchange rate regimes: The case of Latin America. International Economics, 2016.

ROGOFF, K. Equilibrium Political Budget Cycles. American Economic Review, March, 80(1), pp. 21-36. (1990).

ROGOFF, Kenneth; SIBERT, Anne. Elections and Macroeconomic Policy Cycles. The Review of Economic Studies v. 55, n. 1, p. 1-16, 1988. crossref https://doi.org/10.2307/2297526

STEIN, Ernesto H; STREB, Jorge M. Elections and the timing of devaluations. Journal of International Economics v. 63, p. 119-145, 2004. crossref https://doi.org/10.1016/S0022-1996(03)00040-0

TERRA, Cristina; VALLADARES, Frederico. Real exchange rate misalignments. International Review of Economics and Finance v. 19, n. 1, p. 119144, 2010. Disponível em: < http://dx.doi.org/10.1016/j.iref.2009.05.004>.

VIDEIRA, Raphael Almeida. Ciclos Políticos no Brasil. Fundação Getúlio Vargas, 2010. Disponívelem: <http://bibliotecadigital.fgv.br/dspace/handle/10438/8314>.

WOOLDRIDGE, Jeffrey M. Introdução a Econometria: Uma Abordagem Moderna. Cengage Learning. 2011.

WORD BANK - Disponível em https://data.worldbank.org/. Acesso em Agosto de 2016. 


\section{APÊNDICE}

Tabela 1A - Testes de diagnóstico para a variável representativa do momento eleitoral com dummy para o Mercosul

\begin{tabular}{|c|c|c|c|}
\hline Variáveis Independentes & $\begin{array}{l}\text { Pooled } \\
\text { (1) }\end{array}$ & $\begin{array}{c}\text { Efeito Aleatório } \\
(2)\end{array}$ & $\begin{array}{c}\text { Efeito Fixo } \\
\text { (3) }\end{array}$ \\
\hline $\begin{array}{c}\text { Grau de Abertura Comer- } \\
\text { cial }\end{array}$ & $\begin{array}{c}14,155 \\
(0,079) *\end{array}$ & $\begin{array}{c}14,155 \\
(0,076) *\end{array}$ & $\begin{array}{l}19,873 \\
(0,522)\end{array}$ \\
\hline Taxa de Juros dos EUA & $\begin{array}{c}-2,631 \\
(0,018) * *\end{array}$ & $\begin{array}{c}-2,631 \\
(0,015) * *\end{array}$ & $\begin{array}{c}-1,563 \\
(0,170) * *\end{array}$ \\
\hline Termos de Troca & $\begin{array}{c}0,023 \\
(0,675)\end{array}$ & $\begin{array}{l}0,0231 \\
(0,674)\end{array}$ & $\begin{array}{c}0,100 \\
(0,078) * *\end{array}$ \\
\hline Tamanho do Governo & $\begin{array}{l}-0,418 \\
(0,029)\end{array}$ & $\begin{array}{c}-0,418 \\
(0,026)^{* *}\end{array}$ & $\begin{array}{c}0,154 \\
(0,498)\end{array}$ \\
\hline D. Mercosul & $\begin{array}{c}2,601 \\
(0,590)\end{array}$ & $\begin{array}{c}2,601 \\
(0,589)\end{array}$ & $\begin{array}{c}3,598 \\
(0,418)\end{array}$ \\
\hline Constante & $\begin{array}{c}126,842 \\
(0,000) * * * *\end{array}$ & $\begin{array}{c}126,842 \\
(0,000) * * * *\end{array}$ & $\begin{array}{l}53,551 \\
(0,132)\end{array}$ \\
\hline Teste de Chow & - & - & $(0,000) * * *$ \\
\hline Teste de Breusch-Pagan & $(1,000)$ & - & - \\
\hline Teste de Hausman & - & - & $(0,001)^{* * *}$ \\
\hline Teste de Wald & - & - & $(0,000) * * \cdots$ \\
\hline Teste de Wooldridge & - & - & $(0,025)$ \\
\hline Observações & 90 & 90 & 90 \\
\hline
\end{tabular}

Nota: *** Significante à $1 \%$; ** Significante à $5 \%$; * Significante à $10 \%$. O número entre parênteses é o p-valor. Fonte: Elaboração própria. 
124 C. S. Teles; J. H. Alves; S. W. D'Amato - A taxa de câmbio no Mercosul: uma análse...

Tabela 2A - Testes de diagnóstico para a variável representativa do momento eleitoral com dummies por país

\begin{tabular}{|c|c|c|c|}
\hline Variáveis Independentes & $\begin{array}{l}\text { Pooled } \\
(1)\end{array}$ & $\begin{array}{c}\text { Efeito Aleatório } \\
(2) \\
\end{array}$ & $\begin{array}{c}\text { Efeito Fixo } \\
(3) \\
\end{array}$ \\
\hline Grau de Abertura Comercial & $15,237(0,100) * * *$ & $\begin{array}{c}15,237 \\
(0,096) *\end{array}$ & $\begin{array}{l}21,308 \\
(0,500)\end{array}$ \\
\hline Taxa de Juros dos EUA & $\begin{array}{c}-2,542 \\
(0,022) * *\end{array}$ & $\begin{array}{c}-2,542 \\
(0,020) * *\end{array}$ & $\begin{array}{l}-1,486 \\
(0,197)\end{array}$ \\
\hline Termos de Troca & $\begin{array}{c}0,027 \\
(0,619)\end{array}$ & $\begin{array}{l}0,0278 \\
(0,617)\end{array}$ & $\begin{array}{c}0,103 \\
(0,072) *\end{array}$ \\
\hline Tamanho do Governo & $\begin{array}{c}-0,364 \\
(0,066) * *\end{array}$ & $\begin{array}{l}-0,3643 \\
(0,063) *\end{array}$ & $\begin{array}{c}0,155 \\
(0.502)\end{array}$ \\
\hline D. Argentina & $\begin{array}{l}12,634 \\
(0,221)\end{array}$ & $\begin{array}{l}12,634 \\
(0,218)\end{array}$ & $\begin{array}{c}5,450 \\
(0.590)\end{array}$ \\
\hline D. Brasil & $\begin{array}{c}4,210 \\
(0,652)\end{array}$ & $\begin{array}{c}4,210 \\
(0,651)\end{array}$ & $\begin{array}{c}5,803 \\
(0.536)\end{array}$ \\
\hline D. Paraguai & $\begin{array}{c}4,489 \\
(0,680)\end{array}$ & $\begin{array}{c}4,489 \\
(0,679)\end{array}$ & $\begin{array}{l}2,0792 \\
(0,837)\end{array}$ \\
\hline D. Uruguai & $\begin{array}{c}3,542 \\
(0,724)\end{array}$ & $\begin{array}{c}3,542 \\
(0,722)\end{array}$ & $\begin{array}{l}-1,694 \\
(0,867)\end{array}$ \\
\hline Constante (D. Venezuela) & $\begin{array}{c}119,494 \\
(0,000) * * *\end{array}$ & $\begin{array}{c}119,494 \\
(0,000) * * * \%\end{array}$ & $\begin{array}{l}52,067 \\
(0.150)\end{array}$ \\
\hline Teste de Chow & - & - & $(0.002)$ \\
\hline Teste de Hausman & - & - & $(0.003) * * * *$ \\
\hline Teste de Breusch-Pagan & $(1.000)$ & - & \\
\hline Teste de Ward & - & - & $(0.000) * * *$ \\
\hline Teste de Wooldridge & - & - & $(0.023) * *$ \\
\hline Observações & 90 & 90 & 90 \\
\hline
\end{tabular}

Nota: *** Significante à $1 \%$; * Significante à $5 \%$; * Significante à $10 \%$. O número entre parênteses é o p-valor. Fonte: Elaboração própria.

Recebido em 20.03.17

Aprovado em 23.02.18 